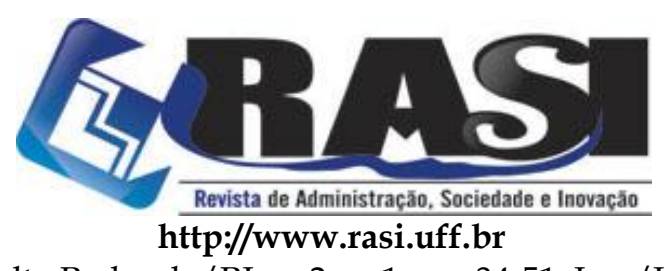

RASI, Volta Redonda/RJ, v. 2, n. 1, pp. 34-51, Jan./Jun. 2016

\title{
Desenvolvimento de um plano de gerenciamento de resíduos de serviços de saúde, para unidade de suporte de pacientes portadores do HIV
}

Fernanda Augusta de Oliveira Melo, Joice Andrade de Araújo, Luiza Machado Mothé

\begin{abstract}
RESUMO
O presente estudo aborda o gerenciamento dos Resíduos de Serviços de Saúde (RSS) de uma Associação, situada na cidade de Volta Redonda/RJ. Seu objetivo é desenvolver um Plano de Gerenciamento de Resíduos de Serviços de Saúde (PGRSS) para a unidade em questão. Trata-se de um estudo realizado através de observações referentes ao gerenciamento do RSS, realizadas em todas as dependências do estabelecimento, além do questionamento aos vários funcionários. Verificou-se que a unidade estudada gera mensalmente $181,388 \mathrm{~kg}$, sendo aproximadamente $79 \%$ destes os contaminados, e que os resíduos gerados no local são classificados como do grupo A (resíduos infectantes), grupo B (químicos), grupo D (resíduo comum) e grupo E (perfurocortantes). A partir da necessidade da unidade foram propostas novas medidas de manuseio do resíduo, baseadas na RDC no 306 da ANVISA, visando maior eficácia na segregação e, consequentemente, menor geração de resíduos contaminados. Através do estudo pôde-se concluir que a aplicação do PGRSS é de grande importância para a proteção da sociedade além de minimizar o impacto gerado pelo descarte do RSS no meio ambiente.
\end{abstract}

PALAVRAS-CHAVE: Resíduos de serviço de saúde; Gestão de resíduos; Plano de gerenciamento de resíduos.

\section{ABSTRACT}

This study addresses the management of Health Services Waste of an association, in the city of Volta Redonda / RJ. Their goal was to develop a Plan of Health Services Waste Management for the unit in question. This is a study by observations concerning the management of the Health Services Waste held in all premises of the establishment, in addition to questioning the various employees. It was found that the studied unit monthly produces $181.388 \mathrm{~kg}$, approximately $79 \%$ of those infected, and that the waste generated on site are classified as Group A (infectious waste), group B (Chemical), group D (common waste) and group E (sharps). From the necessity of new proposals unit were handling measures of the residue based on the RDC $n^{\circ} 306$ ANVISA, aimed more effective segregation and consequently, generate less contaminated waste. Through the study it can be concluded that the application of Plan of Health Services Waste Management is of great importance to the protection of society while minimizing the impact generated by the Health Services Waste disposal in the environment.

KEYWORDS: Health Services Waste; Waste Management; Plan Waste Management.

\section{Universidade \\ Federal \\ Fluminense}

R. Desembargador Ellis Hermydio Figueira, 783, Bloco A, sl. 218, Aterrado. 27213-415 - Volta Redonda, RJ - Brasil

www.uff.br

Copyright (C) 2016 RASI. Todos os direitos, até mesmo de tradução, são reservados. É permitido citar parte de artigos sem autorização prévia, desde que seja identificada a fonte. 


\section{Desenvolvimento de um plano de gerenciamento de resíduos de serviços de saúde,} para unidade de suporte de pacientes portadores do HIV

\section{Introdução}

Os resíduos de serviços de saúde (RSS), conhecidos popularmente como lixo hospitalar são resíduos que podem conter agentes patogênicos, gerados em estabelecimentos que exercem atividades relacionadas ao atendimento de saúde, seja humana ou animal.

Os RSS podem, devido ao potencial de patogenicidade, ter alto potencial de risco à saúde e ao meio ambiente. Podendo causar contaminação do solo, águas subterrâneas e superficiais, entre outros, além da propagação de doenças, devido ao gerenciamento e disposição inadequados do resíduo.

Segundo a Resolução CONAMA n ${ }^{\circ}$ 358/00 (art. $3^{\circ}$ ), cabe aos geradores de resíduos de serviços de saúde e ao responsável legal o gerenciamento deste tipo de resíduo, que deve englobar todas as etapas, desde a geração até a destinação final ambientalmente adequada. Ela define também, em seu $4^{\circ}$ artigo, que a elaboração e implantação do Plano de Gerenciamento de Resíduos de Saúde (PGRSS) também é responsabilidade dos seus geradores, que por ser um documento norteador de todas as etapas do gerenciamento dos RSS, é de extrema importância para a preservação da saúde pública.

Todavia, esse assunto ainda é tratado, muitas vezes, com certo descaso oferecendo risco, principalmente à segurança do trabalhador desta área. Segundo o Panorama de Resíduos Sólidos no Brasil- ABRELPE (2012), apenas uma parcela dos municípios adotaram sistemas específicos para coleta total ou parcial os RSS, e geralmente o fazem apenas para os resíduos gerados em unidades públicas de saúde.

Dado o exposto, este projeto visa suscitar informações para estabelecimentos que, de alguma forma, fornecem apoio e suporte aos portadores do HIV. Mediante a problemática apresentada, torna-se clara a necessidade em adotar medidas preventivas com vista a um ambiente saudável e, por consequência uma melhor qualidade de vida aos residentes e frequentadores da unidade de estudo. O PGRSS, sendo uma medida preventiva quanto aos riscos mencionados acima, através de normas, critérios técnicos, legislações e orientações para o manuseio do resíduo fornecem segurança para a comunidade promovendo a preservação do meio ambiente como um todo.

\section{Resíduos Sólidos}

Segundo a norma NBR 10004 (2004) da Associação Brasileira de Normas Técnicas (ABNT), resíduos sólidos são: resíduos nos estados sólidos ou semi-sólidos, gerados durante atividades de origem industrial, doméstica, hospitalar, comercial, agrícola, de serviços e de varrição.

Ainda na mesma norma é definida a classificação dos resíduos sólidos que é dividida em resíduos de Classe I (Perigosos) e de Classe II (Não perigosos), esta última classe é subdividida em Classe II A (Não inertes) e Classe II B (inertes).

2.1 Resíduos de Serviços de Saúde 
Segundo a resolução ${ }^{\circ} 358$ do Conama (parágrafo 10, artigo segundo), resíduos de serviços de saúde são os gerados em atividades relacionadas com:

$\mathrm{O}$ atendimento à saúde humana ou animal, inclusive os serviços de assistência domiciliar e de trabalhos de campo; laboratórios analíticos de produtos para saúde; necrotérios, funerárias e serviços onde se realizem atividades de embalsamamento (tanatopraxia e somatoconservação); serviços de medicina legal; drogarias e farmácias inclusive as de manipulação; estabelecimentos de ensino e pesquisa na área de saúde; centros de controle de zoonoses; distribuidores de produtos farmacêuticos; importadores, distribuidores e produtores de materiais e controles para diagnóstico in vitro; unidades móveis de atendimento à saúde; serviços de acupuntura; serviços de tatuagem, entre outros similares. (BRASIL, 2005)

Este tipo de resíduo é classificado como resíduo perigoso pela NBR 10.004 (2004) devido a sua possível patogenicidade. Se não for manejado, tratado e descartado conforme exigem as normas vigentes podem oferecer grande risco à saúde da população, e principalmente aos profissionais que lidam diretamente com ele.

\subsection{Classificação dos Resíduos de Serviços de Saúde}

A classificação dos RSS na norma NBR 12808 (1993) da ABNT divide resíduos em questão em apenas três tipos: A, B e C. O tipo A são os infectantes que contém resíduos biológicos, sangue e hemoderivados, resíduos de procedimentos cirúrgicos, anatomopatológico e exsudato, resíduos perfurantes ou cortantes, animal contaminado e resíduos gerados em assistência ao paciente. O tipo B são os resíduos especiais, estão inseridos os rejeitos radioativos, resíduos farmacêuticos e resíduos químicos perigosos. E o tipo C são os resíduos comuns, que por serem semelhantes aos resíduos domésticos, não oferecem risco à saúde pública e ao meio ambiente.

A Agência Nacional de Vigilância Sanitária (ANVISA) detalha mais ainda a classificação dos resíduos de saúde na RDC no 306 (2004) dividindo-os em cinco grupos. São eles:

Grupo A: possuem possivelmente a presença de agentes biológicos que podem apresentar riscos de infecção. São subdivididos também em cinco grupos, descritos no Quadro 1. 
Quadro 1 - Classificação do Grupo A dos Resíduos de Serviços de Saúde.

\begin{tabular}{|c|c|}
\hline \multicolumn{2}{|r|}{ GRUPO A } \\
\hline \multirow{4}{*}{ A1 } & $\begin{array}{l}\text { 1.1 Culturas e estoques de microrganismos; resíduos de fabricação de produtos biológicos, } \\
\text { exceto os hemoderivados; descarte de vacinas de microrganismos vivos ou atenuados; meios de } \\
\text { cultura e instrumentais utilizados para transferência, inoculação ou mistura de culturas; resíduos } \\
\text { de laboratórios de manipulação genética; }\end{array}$ \\
\hline & $\begin{array}{l}\text { 1.2 Resíduos resultantes da atenção à saúde de indivíduos ou animais, com suspeita ou certeza de } \\
\text { contaminação biológica por agentes classe de risco 4, microrganismos com relevância } \\
\text { epidemiológica e risco de disseminação ou causador de doença emergente que se torne } \\
\text { epidemiologicamente importante ou cujo mecanismo de transmissão seja desconhecido; }\end{array}$ \\
\hline & $\begin{array}{l}\text { 1.3 Bolsas transfusionais contendo sangue ou hemocomponentes rejeitadas por contaminação ou } \\
\text { por má conservação, ou com prazo de validade vencido, e aquelas oriundas de coleta incompleta; }\end{array}$ \\
\hline & $\begin{array}{l}\text { 1.4 Sobras de amostras de laboratório contendo sangue ou líquidos corpóreos, recipientes e } \\
\text { materiais resultantes do processo de assistência à saúde, contendo sangue ou líquidos corpóreos } \\
\text { na forma livre; }\end{array}$ \\
\hline A2 & $\begin{array}{l}\text { 2.1 Compostos por carcaças, peças anatômicas, vísceras e outros resíduos provenientes de } \\
\text { animais submetidos a processos de experimentação com inoculação de microrganismos, bem } \\
\text { como suas forrações, e os cadáveres de animais suspeitos de serem portadores de } \\
\text { microrganismos de relevância epidemiológica e com risco de disseminação, que foram } \\
\text { submetidos ou não a estudo anátomo-patológico ou confirmação diagnostica; }\end{array}$ \\
\hline A3 & $\begin{array}{l}\text { 3.1 Contém peças anatômicas (membros) do ser humano; produto de fecundação sem sinais } \\
\text { vitais, com peso menor que } 500 \text { gramas ou estatura menor que } 25 \text { centímetros ou idade } \\
\text { gestacional menor que } 20 \text { semanas, que não tenham valor científico ou legal e não tenha havido } \\
\text { requisição pelo paciente ou familiares; }\end{array}$ \\
\hline \multirow{8}{*}{ A4 } & 4.1 Kits de linhas arteriais, endovenosas e dializadores, quando descartados; \\
\hline & $\begin{array}{l}\text { 4.2 Filtros de ar e gases aspirados de área contaminada; membrana filtrante de equipamento } \\
\text { médico-hospitalar e de pesquisa, entre outros similares; }\end{array}$ \\
\hline & $\begin{array}{l}\text { 4.3 Sobras de amostras de laboratório e seus recipientes contendo fezes, urina e secreções, } \\
\text { provenientes de pacientes que não contenham e nem sejam suspeitos de conter agentes Classe de } \\
\text { Risco } 4 \text {, e nem apresentem relevância epidemiológica e risco de disseminação, ou } \\
\text { microrganismo causador de doença emergente que se torne epidemiologicamente importante ou } \\
\text { cujo mecanismo de transmissão seja desconhecido ou com suspeita de contaminação com príons; }\end{array}$ \\
\hline & $\begin{array}{l}\text { 4.4 Resíduos de tecido adiposo proveniente de lipoaspiração, lipoescultura ou outro } \\
\text { procedimento de cirurgia plástica que gere este tipo de resíduo; }\end{array}$ \\
\hline & $\begin{array}{l}4.5 \text { Recipientes e materiais resultantes do processo de assistência à saúde, que não contenha } \\
\text { sangue ou líquidos corpóreos na forma livre; }\end{array}$ \\
\hline & $\begin{array}{l}\text { 4.6 Peças anatômicas (órgãos e tecidos) e outros resíduos provenientes de procedimentos } \\
\text { cirúrgicos ou de estudos anatomopatológicos ou de confirmação diagnóstica; }\end{array}$ \\
\hline & $\begin{array}{l}\text { 4.7 Carcaças, peças anatômicas, vísceras e outros resíduos provenientes de animais não } \\
\text { submetidos a processos de experimentação com inoculação de microrganismos, bem como suas } \\
\text { forrações; }\end{array}$ \\
\hline & 4.8 Bolsas transfusionais vazias ou com volume residual pós-transfusão. \\
\hline A5 & $\begin{array}{l}\text { 5.1 Possui órgãos, tecidos, fluidos orgânicos, materiais perfurocortantes ou escarificantes e } \\
\text { demais materiais resultantes da atenção à saúde de indivíduos ou animais, com suspeita ou } \\
\text { certeza de contaminação com príons. }\end{array}$ \\
\hline
\end{tabular}

Fonte: Adaptada pelo autor - ANVISA, 2004.

Grupo B: são os que contêm substâncias químicas, que dependendo das suas características de inflamabilidade, corrosividade, reatividade e toxicidade pode apresentar dano à saúde pública e ao meio ambiente. Elas estão especificadas no Quadro 2. 
Quadro 2 - Componentes do Grupo B dos Resíduos de Serviços de Saúde.

\begin{tabular}{|c|l|}
\hline \multicolumn{1}{|c|}{ GRUPO B } \\
\hline $\mathbf{1}$ & $\begin{array}{l}\text { Produtos hormonais e produtos antimicrobianos; citostáticos; antineoplásicos; } \\
\text { imunossupressores; digitálicos; imuno moduladores; anti-retrovirais, quando descartados } \\
\text { por serviços de saúde, farmácias, drogarias e distribuidores de medicamentos ou } \\
\text { apreendidos e os resíduos e insumos farmacêuticos dos medicamentos controlados pela } \\
\text { Portaria MS 344/98 e suas atualizações. }\end{array}$ \\
\hline $\mathbf{2}$ & $\begin{array}{l}\text { Resíduos de saneantes, desinfetantes, resíduos contendo metais pesados; reagentes para } \\
\text { laboratório, inclusive os recipientes contaminados por estes. }\end{array}$ \\
\hline $\mathbf{3}$ & Efluentes de processadores de imagem (reveladores e fixadores). \\
\hline $\mathbf{4}$ & Efluentes dos equipamentos automatizados utilizados em análises clínicas \\
\hline $\mathbf{5}$ & $\begin{array}{l}\text { Demais produtos considerados perigosos, conforme classificação da NBR 10.004 da ABNT } \\
\text { (tóxicos, corrosivos, inflamáveis e reativos). }\end{array}$ \\
\hline
\end{tabular}

Fonte: Adaptada pelo autor - ANVISA, 2004.

Grupo D: são os que não oferecem risco biológico, químico ou radiológico à saúde ou ao meio ambiente. Neste grupo estão os resíduos gerados em banheiro, sobras de alimento, resíduos gerados na área administrativa, podas de árvores, entre outros, estes podem ser equiparados com os resíduos gerados em domicílios.

Grupo E: são os materiais perfurocortantes ou escarificantes e similares.

A correta classificação dos resíduos é de extrema importância e permite a manipulação com os devidos cuidados pelos geradores sem oferecer risco aos trabalhadores e ao meio ambiente.

\subsection{Manipulação dos Resíduos de Serviços de Saúde}

A figura 1 esquematiza todas as etapas necessárias para a manipulação dos resíduos de serviços de saúde segundo a RDC ANVISA nº 306 (2004).

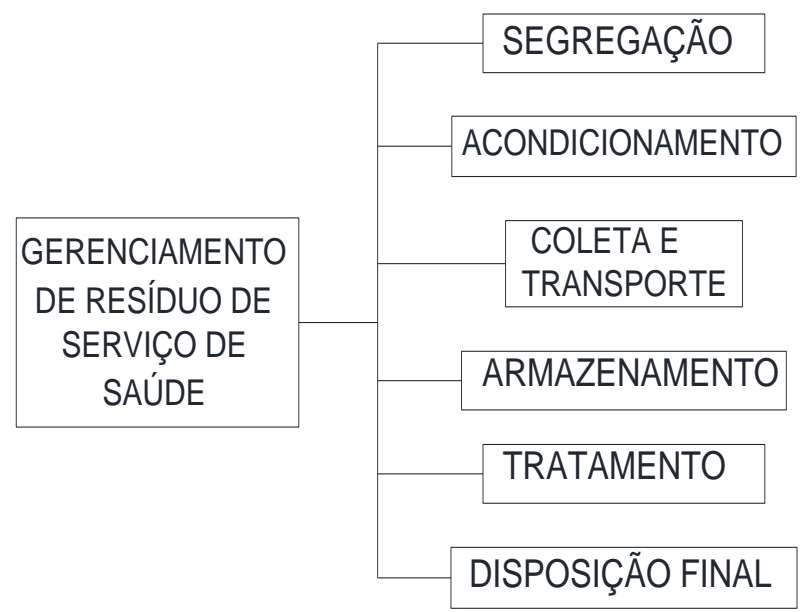


Figura 1 - Esquema das etapas necessárias para a manipulação dos RSS.

Fonte: Elaborada pelo autor, 2014.

Todas as etapas mostradas na figura 1 integram a manipulação dos RSS e devem seguir a norma da ABNT NBR 12809 (1993) além de atender a RDC no 306 (2004). A norma esclarece quanto aos procedimentos exigidos para manusear todos os tipos de resíduos gerados no serviço de saúde, de maneira a garantir a higiene e segurança no processamento dentro do estabelecimento.

Para o manuseio dos RSS os funcionários devem utilizar os equipamentos de proteção individual (EPIs). E ainda, todos os profissionais de saúde devem ser treinados para segregar adequadamente o resíduo e conhecer o sistema de identificação.

\subsubsection{Segregação}

Segregação é a separação isolada dos resíduos de acordo com suas características, baseada na classificação normativa dos resíduos. Em seu Manual de Gerenciamento de RSS, a ANVISA afirma que "Sem uma segregação adequada cerca de 70 a $80 \%$ dos resíduos gerados em serviços de saúde que não apresentam risco acabam potencialmente contaminados" (Brasil, 2006).

Ou seja, os resíduos não contaminados entram em contato com resíduos contaminados durante uma segregação inadequada, aumentando o volume de resíduos contaminados e gerando mais gastos.

As vantagens da correta segregação do resíduo em questão na fonte geradora são:

Redução dos riscos para a saúde e o meio ambiente: a mistura dos resíduos de características diferentes causa a contaminação dos resíduos não perigosos tornando-os perigosos também, a segregação correta impede que os resíduos potencialmente infectantes ou especiais contaminem os resíduos em geral;

Diminuição dos gastos: a segregação correta minimiza o volume do resíduo que terá tratamento especial.

\subsubsection{Acondicionamento}

O acondicionamento dos RSS consiste na guarda do resíduo em questão, já segregado, em recipientes apropriados, impermeáveis e com capacidade de suprir a geração diária gerada no estabelecimento. É importante porque facilita o transporte do resíduo e protege de riscos.

Os resíduos devem ser acondicionados em sacos de material resistente a ruptura e vazamento, baseado na NBR 9191 (2000) da ABNT, respeitados os limites de peso de cada saco, sendo proibido o seu esvaziamento ou reaproveitamento. Os sacos devem estar contidos em recipientes de material que possa ser lavado, que também seja resistente à ruptura e vazamento, que possua tampa com sistema de abertura sem contato manual, e ser resistente ao tombamento.

Os resíduos perfurocortantes devem ser acondicionados em caixas de papelão rígido (figura 2) apropriadas para seu tipo, o que impede que a agulha ou outros materiais furem o recipiente, e o resíduo é descartado junto com a caixa lacrada. 


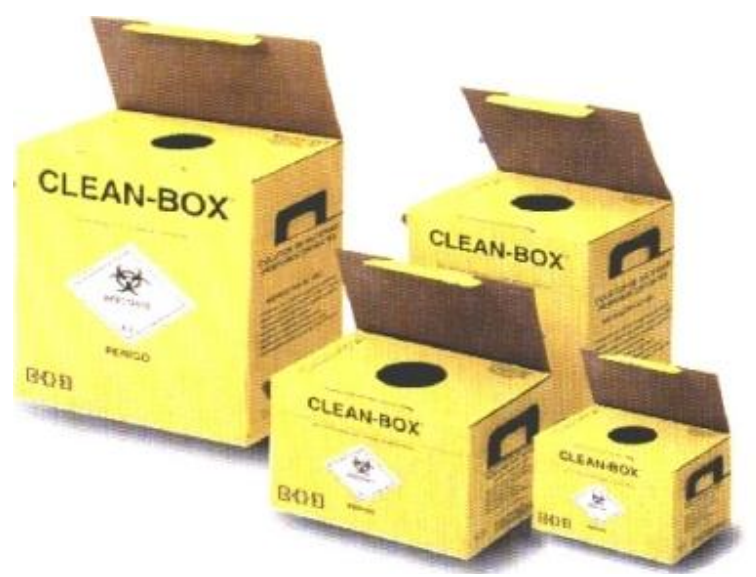

Figura 2- Exemplo de recipientes para acondicionamento de resíduos perfurocortantes.

Fonte: Fiocruz, 2014.

As embalagens de acondicionamento deve obter identificação informando o resíduo que ali está contido e informando também formas corretas de manejo do objeto. Para a identificação devem-se utilizar símbolos, cores e frases de acordo com as exigências referenciadas na norma NBR 7500 (2003) da ABNT.

\subsubsection{Coleta e armazenamento}

A norma NBR 12809 (1993) estabelece que cada unidade geradora deve possuir uma sala de resíduos adequada para o armazenamento interno dos recipientes obedecendo às normas padrões do Ministério da Saúde e com alguns requisitos, porém elimina a obrigação para os pequenos geradores. Logo, estabelecimentos com geração semanal menor que $700 \mathrm{~L}$ podem encaminhar os recipientes contendo os resíduos diretamente para o abrigo reduzido de resíduos (armazenamento externo).

A norma ABNT 7500 (2000) estabelece características mínimas exigidas para o abrigo reduzido de resíduos (armazenamento externo): o local deve ser destinado exclusivamente para a reserva temporária de RSS devidamente acondicionados, ter dimensões que suportem a produção de até três dias, ser constituído de material liso, impermeável, lavável e de cor branca, ter ventilação restrita, piso com caimento mínimo, não possuir instalação elétrica e possuir porta com o símbolo adequado. $\mathrm{O}$ local deve ser higienizado após a coleta ou quando ocorrer derramamento, e o efluente da higienização deve receber tratamento adequado.

\subsubsection{Transporte}

O transporte de RSS é feito tanto na parte interna quanto na parte externa do estabelecimento e deve atender roteiro previamente definido (Figura 3). 


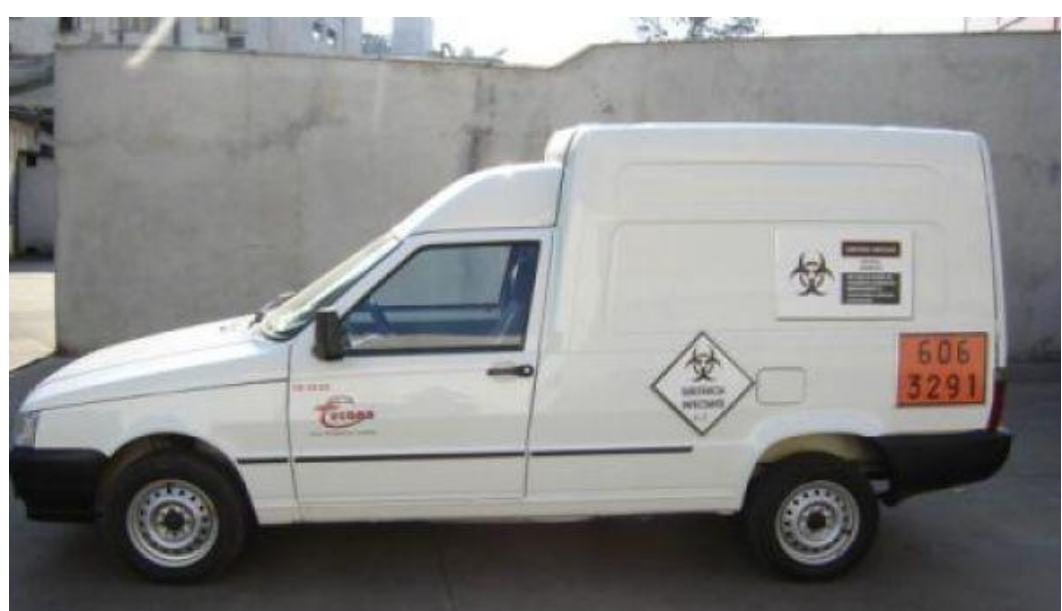

RSS.

Figura 3 - Exemplos de veículos utilizados para o transporte externo do

Fonte: Grupo Tucano, 2014.

O ideal é que o transporte de resíduos não seja feito em horários de maior fluxo de pessoas no estabelecimento, e principalmente em horários de distribuição de refeição e roupas, horários de visita familiar, entre outros.

As recomendações gerais para o transporte são: diferentes tipos de veículos podem ser utilizados para o transporte externo, de pequeno à grande porte, e os sacos nunca devem ser retirados do suporte durante o transporte tanto interno quanto externo.

\subsubsection{Simbologia}

Todos os recipientes, os sacos de acondicionamento, assim como os automóveis para transporte de RSS devem estar identificados com a simbologia de resíduos infectantes de acordo com a NBR 7500 (2003), indicando os riscos e cuidados a serem tomados em todas as etapas que envolvem a manipulação dos resíduos perigosos, no caso, resíduos de serviços de saúde.

Para cada tipo de resíduo de serviço de saúde existe uma figura designativa que informa os riscos oferecidos pelo resíduo ali contido. Os símbolos estão contidos na figura 4. 


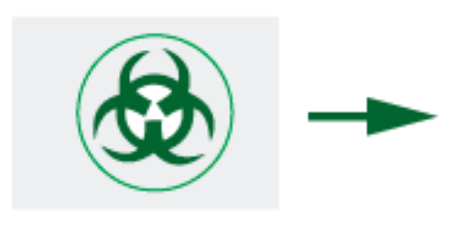

Resíduos do grupo A e E são identificados pelo símbolo de substância infectante e frases de RISCO BIOLÓGICO ou RESÍDUO PERFUROCORTANTE.
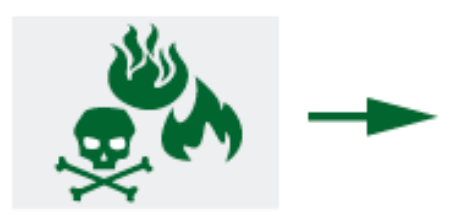

Residuos do grupo B são identificados atravez do símbolo de risco e com discriminaçăo de de substância química e frases de risco como: QUIMICO OU INFLAMAVEL.
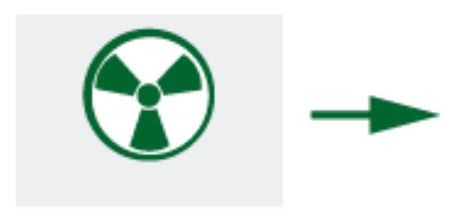

Os rejeitos do grupo $\mathrm{C}$ săo representados pelo simbolo internacional de presença de radiação Ionizante acrecido a expressão MATERIAL RADIOATIVO.

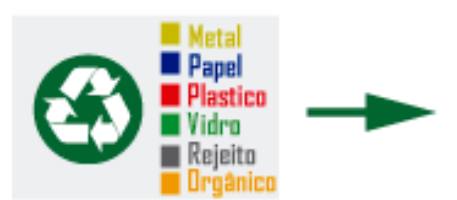
Os rejeitos do grupo D săo representados pelo símbolo de RECICLAGEM e o rotulado correspondente segundo o tipo de material. Saúde.

Figura 4-Símbolos de Identificação dos Grupos de Resíduos de Serviços de

Fonte: RETEC, 2014.

\subsubsection{Tratamento e disposição final ambientalmente adequada}

Pela resolução da ANVISA no 306, o tratamento do RSS consiste na aplicação de métodos, técnicas ou processos que reduzam ou eliminem o risco de contaminação, de acidentes ocupacionais ou de danos ao meio ambiente, através da modificação das características dos riscos inerentes aos resíduos.

A resolução CONAMA $n^{\circ} 358$ estabelece que os resíduos do grupo A (com presença de agentes biológicos) não podem ser reutilizados ou reciclados e os grupos $\mathrm{A} 1, \mathrm{~A} 2, \mathrm{~A} 5$ e o grupo B (que apresentam risco devido à sua característica química e físico-química), exceto resíduos os que não apresentam características de periculosidade, necessitam de tratamento prévio antes da destinação final; o grupo C (radioativos) deve obedecer às exigências da CNEN; os resíduos do grupo D (resíduo comum), quando passíveis de recuperação, devem ser encaminhados ao aterro sanitário de resíduos sólidos urbanos; e os do grupo E (perfurocortantes) deve ter tratamento químico de acordo com o tipo de contaminação (química, biológica ou radiológica).

$\mathrm{O}$ anexo II da CONAMA $n^{\circ} 358$ esclarece em um quadro os critérios mínimos exigidos para a disposição final de resíduos de serviços de saúde, como mostra o quadro 3. 
Quadro 3- Critérios mínimos para disposição final de resíduos de serviços de saúde exclusivamente.

\begin{tabular}{|c|c|}
\hline I) Quanto à seleção de área: & $\begin{array}{l}\text { a) não possuir restrições quanto ao zoneamento ambiental } \\
\text { (Afastamento de Unidades de Conservação ou áreas correlatas); } \\
\text { b) respeitar as distâncias mínimas estabelecidas pelos órgãos } \\
\text { ambientais competentes de ecossistemas frágeis, recursos hídricos } \\
\text { superficiais e subterrâneos; }\end{array}$ \\
\hline $\begin{array}{l}\text { II) Quanto à segurança } \\
\text { sinalização: }\end{array}$ & $\begin{array}{l}\text { a) sistema de controle de acesso de veículos, pessoas não } \\
\text { autorizadas e animais, sob vigilância contínua; e } \\
\text { b) sinalização de advertência com informes educativos quanto aos } \\
\text { perigos envolvidos. }\end{array}$ \\
\hline III) Quanto aos aspectos técnicos: & $\begin{array}{l}\text { a) sistemas de drenagem de águas pluviais; } \\
\text { b) coleta e disposição adequada dos percolados; } \\
\text { c) coleta de gases; } \\
\text { d) impermeabilização da base e taludes; e } \\
\text { e) monitoramento ambiental. }\end{array}$ \\
\hline $\begin{array}{l}\text { IV) Quanto ao processo de } \\
\text { disposição final de resíduos de } \\
\text { serviços de saúde: }\end{array}$ & $\begin{array}{l}\text { a) disposição dos resíduos diretamente sobre o fundo do local; } \\
\text { b) acomodação dos resíduos sem compactação direta; } \\
\text { c) cobertura diária com solo, admitindo-se disposição em } \\
\text { camadas; } \\
\text { d) cobertura final; e } \\
\text { e) plano de encerramento. }\end{array}$ \\
\hline
\end{tabular}

Fonte: CONAMA, 2005.

\subsection{Normas Vigentes}

As legislações e normas técnicas específicas quanto ao gerenciamento dos RSS estão expostas no quadro 4 , abordando seus respectivos assuntos e definições.

Quadro 4 - Principais legislações e normas aplicadas ao gerenciamento dos RSS.

\begin{tabular}{|c|c|c|c|}
\hline \multicolumn{4}{|c|}{ PRINCIPAIS LEGISLAÇÕES E NORMAS } \\
\hline TÍTULO & ANO & ASSUNTO & DEFINIÇÃ̃O \\
\hline CONAMA 358 & 2005 & $\begin{array}{l}\text { Tratamento e } \\
\text { disposição final }\end{array}$ & $\begin{array}{l}\text { Dispõe sobre o tratamento e a disposição final dos } \\
\text { resíduos dos serviços de saúde e dá outras providências. }\end{array}$ \\
\hline ‘ NBR 7500 & 2000 & Simbologia & $\begin{array}{l}\text { Símbolos de risco e manuseio para o transporte e } \\
\text { armazenamento de materiais. }\end{array}$ \\
\hline NBR 9190 & 2000 & Sacos plásticos & Classificação de sacos plásticos para acondicionar o lixo. \\
\hline ‘ NBR 9191 & 2000 & Sacos plásticos & $\begin{array}{l}\text { Especificação dos sacos plásticos para acondicionamento } \\
\text { de lixo. }\end{array}$ \\
\hline NBR 12807 & 1993 & Terminologia & $\begin{array}{l}\text { Norma que define os termos empregados em resíduos de } \\
\text { serviços de saúde. }\end{array}$ \\
\hline NBR 12808 & 1993 & Classificação & $\begin{array}{l}\text { Norma que classifica os resíduos de serviços de saúde } \\
\text { quanto aos riscos potenciais ao meio ambiente e à saúde } \\
\text { pública, para que tenham gerenciamento adequado. }\end{array}$ \\
\hline NBR 12809 & 1993 & Procedimentos & $\begin{array}{l}\text { Norma que fixa os procedimentos exigíveis para garantir } \\
\text { condições de higiene e segurança no processamento } \\
\text { interno de resíduos infectantes, especiais e comuns, nos } \\
\text { serviços de saúde. }\end{array}$ \\
\hline NBR 12810 & 1993 & Coleta & $\begin{array}{l}\text { Norma que fixa os procedimentos exigíveis para coleta } \\
\text { interna e externa dos resíduos de serviços de saúde, sob } \\
\text { condições de higiene e segurança. }\end{array}$ \\
\hline NBR 13853 & 1993 & Coletores & Coletores para resíduos de serviços de saúde perfurantes \\
\hline
\end{tabular}




\begin{tabular}{|c|c|c|c|}
\hline & & & ou cortantes \\
\hline RDC 306 & 2004 & Gerenciamento & $\begin{array}{l}\text { Resolução que dispõe sobre o Regulamento Técnico para } \\
\text { o gerenciamento de resíduos de serviços de saúde. }\end{array}$ \\
\hline
\end{tabular}

Fonte: Elaborada pelo autor, 2014.

\subsection{Gerenciamento de Resíduos de Serviços de Saúde}

O objetivo de planejar o gerenciamento deste tipo de resíduo é diminuir a produção de resíduos contaminados, além dos resíduos comuns, e dar segurança quanto à manipulação dos resíduos gerados.

Segundo a Resolução da Diretoria Colegiada (RDC) no 306 (Brasil, 2004):

$\mathrm{O}$ gerenciamento dos RSS constitui-se em um conjunto de procedimentos de gestão, planejados e implementados a partir de bases científicas e técnicas, normativas e legais, com o objetivo de minimizar a produção de resíduos e proporcionar aos resíduos gerados, um encaminhamento seguro, de forma eficiente, visando à proteção dos trabalhadores, a preservação da saúde pública, dos recursos naturais e do meio ambiente. (ANVISA, 2004)

\subsubsection{Plano de Gerenciamento de Resíduos em Serviços de Saúde}

Em 1993 foi definida a obrigatoriedade dos estabelecimentos de serviços de saúde de elaborarem o Plano de Gerenciamento de Resíduos (PGR) na Resolução CONAMA $n^{\circ}$ 05/93, que é reforçado nas publicações da Resolução CONAMA n³58/05 e da RDC n ${ }^{\circ}$ 306/04 da ANVISA.

Por ser um documento norteador de todas as etapas do gerenciamento dos RSS, um PGRSS é de extrema importância para a preservação da saúde pública, e deve obedecer "critérios técnicos, legislação ambiental, normas de coleta e transporte dos serviços locais de limpeza urbana e outras orientações" (ANVISA, 2004).

Para a elaboração do plano é necessário um estudo detalhado de cada unidade geradora de resíduos, porque cada uma apresenta sua especificidade. Portanto, considera-se que as medidas e normas do plano de gerenciamento de resíduos devem ser desenvolvidas especificamente para cada unidade.

Como afirma Silva (2004) em sua tese Resíduos de Serviços de Saúde, as vantagens da aplicação do PGRSS são: redução dos impactos ambientais, redução dos acidentes de trabalho e redução do número de infecções hospitalares relacionadas ao manejo dos RSS.

\section{$2.6 \mathrm{O}$ HIV}

O ministério da Saúde, em seu Guia para o Cuidador Domiciliar de Pessoas que vivem com HIV/AIDS, esclarece que a AIDS é uma sigla em inglês que significa, em português, Síndrome da Imunodeficiência Adquirida. O HIV (Vírus da Imunodeficiência Humana) é o vírus que causa a síndrome, ele invade as células responsáveis pela defesa do organismo que resulta na morte destas células debilitando o sistema imunológico da pessoa portadora e, desta forma, facilitando a incidência de doenças oportunistas.

A transmissão é feita através de relações sexuais sem proteção, compartilhamento de agulhas e seringas contaminadas, transfusão de sangue ou 
derivados contaminados, contato do sangue contaminado com cortes, feridas e mucosas, na gravidez, parto ou durante o aleitamento materno. $O$ vírus não é transmitido através de tosse, espirro, através do ar, pelo uso de copos ou talheres, pelo uso de vaso sanitário, cadeiras etc., e também não é transmitido por beijos, abraços, contato com fezes, urina, saliva e excreções em gerais.

O tratamento para a doença está disponível no Sistema Único de Saúde (SUS) e é feito, segundo o Departamento de DST, AIDS e Hepatites Virais (2014), através de acompanhamento periódico com profissionais de saúde e da realização exames. A pessoa diagnosticada toma medicamentos retrovirais que buscam manter o vírus sob controle através da redução da multiplicação do HIV no corpo, recuperando as defesas do organismo, e consequentemente, aumentando a qualidade de vida do portador da doença.

Para que o tratamento dê certo, o soropositivo não pode se esquecer de tomar os remédios ou abandoná-los, porque o vírus pode criar resistência e, com isso, as opções de medicamentos vão diminuir. A adesão ao tratamento é fundamental para a qualidade de vida.

O paciente em tratamento pode e deve levar uma vida normal como qualquer outra pessoa. Ele pode trabalhar, passear, namorar e etc.

A prevenção em relação à infecção desta doença toma muita importância devido ao fato de que a cura da doença ainda não foi descoberta.

O Departamento de DST, AIDS e Hepatites Virais, afirma que até junho de 2012 o Brasil registrou 656.701 casos de AIDS e que a região sudeste possui o maior número de casos acumulados.

Segundo British Broadcasting Corporation (2014), o número de infecções no Brasil com o HIV aumentou $11 \%$, diferente da média global que diminuiu, e o índice de morte atribuído a AIDS aumentou 7\%.

\subsection{Resíduos de Serviços de Saúde e a Saúde do Trabalhador}

Além de provocar doença devido ao descarte inadequado no meio ambiente, os RSS podem infeccionar os trabalhadores através de acidentes que podem ocorrer na fonte geradora onde são manipulados, devido ao resíduo conter organismos patogênicos como, por exemplo, os vírus das hepatites B e C e o HIV, vírus da AIDS. Por isso tornase indispensável o cuidado no manuseio dos resíduos. HIV:

Em sua tese, Silva (1999, p. 18) expõe os fatores de risco na transmissão do

Para os trabalhadores da área hospitalar o fator de risco de maior importância na transmissão da AIDS é o contato com o sangue no ambiente de trabalho. Esta transmissão ocupacional do HIV pode ocorrer em exposição a material infectante, como sangue, principalmente através de acidentes de trabalho produzidos por material perfurocortante.

Forantine (1969 apud SILVA 1999, p.19) afirma que os riscos de acidentes ocupacionais dependem da natureza do material manuseado e dos meios de proteção empregados, além de depender do tipo de atividade exercida, e que não é dada a devida atenção aos riscos de acidentes aos quais o trabalhador e a população estão expostos.

\section{Desenvolvimento do Projeto}


O presente trabalho foi baseado em pesquisa teórica com análise de bibliografia formal, e também pesquisas normativas a fim de compreender o processo de tratamento de resíduos hospitalares para a adoção de políticas ambientais. Inicialmente foi realizada a coleta de dados do objeto desse estudo para sua caracterização através do levantamento dos documentos do estabelecimento, tabelas para quantificação, acompanhamento das atividades diárias, entre outros, a fim de obter um diagnóstico da situação dos resíduos gerados e o seu gerenciamento.

Para a identificação dos tipos de resíduos gerados, do local de geração do resíduo específico e de como é feito o manejo atualmente, realizou-se o acompanhamento de setembro a novembro com visitas intermitentes das atividades da associação. Dado o exposto, foi possível compreender o fluxo dos resíduos desde a geração o acondicionamento para a coleta externa.

\subsection{Caracterização do Estabelecimento}

A Associação de Apoio aos Portadores do Vírus HIV é um abrigo que oferece assistência médica realizada por profissionais em diversas especialidades para portadores do HIV, tais como: clinica geral; clinica médica; dermatologia; homeopatia; ginecologia; gastroenterologia, neurologia, cardiologia; psiquiatria; psicologia; odontologia; assistência social; acompanhamentos fisioterápicos, nutricionais e enfermagem. $\mathrm{O}$ abrigo em questão, objeto de estudo desta pesquisa, pratica suas atividades ininterruptamente e em regime de plantões de 4 horas, possui 4 funcionários e 100 trabalhadores voluntariados que receberam orientações de biossegurança e treinamento para cuidadores.

Atualmente, residem ali sete pacientes e todos estão cadastrados no Departamento de DST, que consiste em um controle governamental de pessoas com doenças sexualmente transmissíveis, e sempre que necessário são levados para recebimento dos antirretrovirais e para exames laboratoriais. Quando ocorre situação de maior gravidade, os pacientes são levados para serem atendidos e/ou internados no hospital São João Batista de Volta Redonda/RJ.

A coleta dos resíduos é realizada por serviço terceirizado pela Prefeitura Municipal, que consiste em duas coletas distintas, a coleta de resíduos comuns e a coleta de RSS. O último é tratado pela empresa terceirizada contratada pela prefeitura, através da incineração ou da autoclavagem para depois ser disposto, da mesma forma que o resíduo comum, na Central de Tratamento de Resíduos (CTR) de Barra Mansa/RJ.

A estrutura física é composta de varanda, auditório, secretaria, sala de administração, dois vestiários, dispensário de remédios, consultório médico, nove banheiros, sala de televisão, sala de fisioterapia, três enfermarias, almoxarifado, expurgo, sala de esterilização, central de medicamentos, refeitório, cozinha, lavanderia e área com varais, garagem, sala para eventos religiosos, depósito de material elétrico, sala de despensa, ferramentaria, sala de utensílios de evento e SOS.

Os resíduos sólidos gerados são segregados em sua geração nos recipientes apropriados e são recolhidos dali por qualquer profissional do turno quando a capacidade do mesmo está quase preenchida.

Verificou-se que o processo de gerenciamento dos resíduos atende em parte a legislação vigente e que há deficiência de informações e orientações quanto ao manejo do resíduo de serviço de saúde. 


\subsection{Geração dos Resíduos}

Para a quantificação dos resíduos gerados na unidade estudada, foram identificados os volumes de todos os recipientes utilizados em cada cômodo e em cima de cada recipiente foi para controlar a coleta dos sacos contendo o resíduo durante uma semana. A tabela foi marcada pelos profissionais, assim que os mesmos recolhiam os sacos com os resíduos do recipiente. O fluxo dos resíduos pode ser observado de acordo com a figura 5

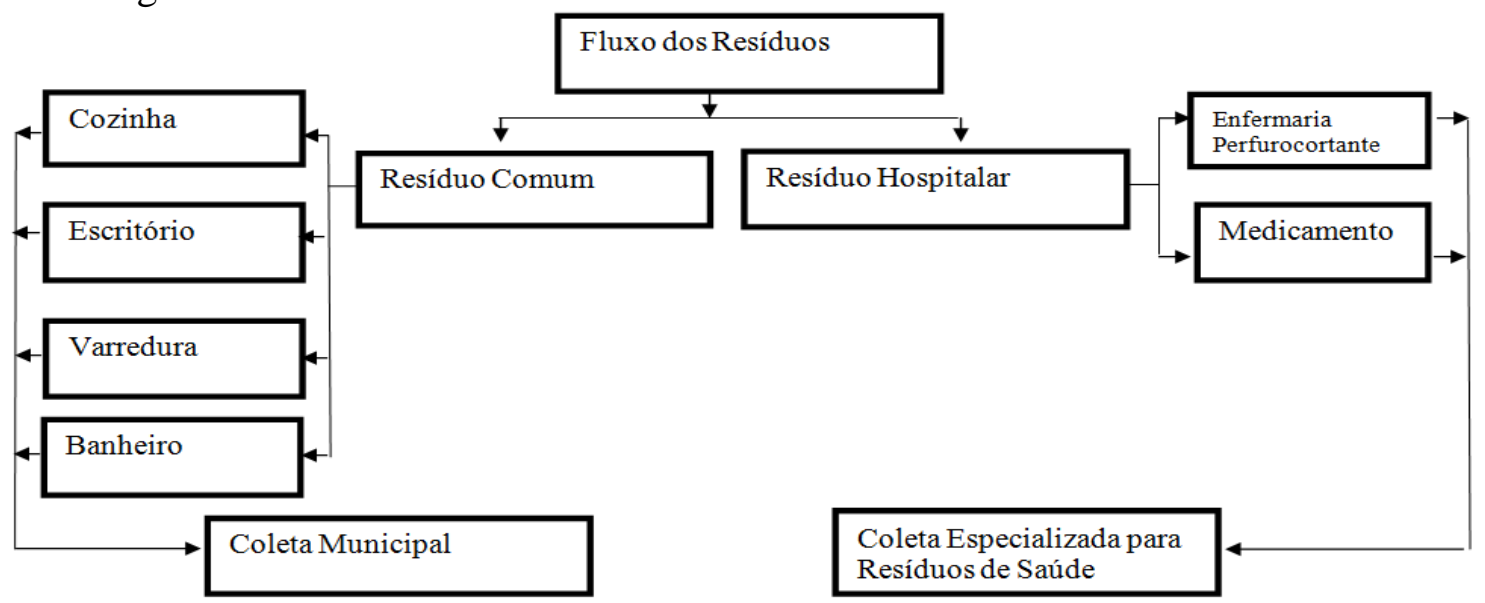

Figura 5- Fluxograma da geração e destinação dos Resíduos

Desta forma obteve-se a quantidade de sacos gerados de resíduo comum, com o volume referente, para então calcular o volume total de resíduos gerados.

Quadro 5 - Volume de Resíduos Comuns Gerados por Semana

\begin{tabular}{|l|c|c|c|c|c|}
\cline { 2 - 6 } \multicolumn{1}{c|}{} & $\begin{array}{c}\text { NÚMERO DE } \\
\text { SACOS }\end{array}$ & VOLUME (L) & $\begin{array}{c}\text { VOLUME } \\
\text { TOTAL }(L)\end{array}$ & $\begin{array}{c}\text { VOLUME } \\
\text { TOTAL }\left(\mathrm{m}^{3}\right)\end{array}$ & $\begin{array}{c}\text { PESO TOTAL } \\
(\mathrm{KG})\end{array}$ \\
\hline Grande (60 L) & 36 & 2160,00 & 2580,00 & 3,04 & 699,2 \\
\hline Pequeno (20L) & 21 & 420,00 & & 6904 \\
\hline
\end{tabular}

Para calcular o peso de resíduo comum gerado, utilizamos o volume estimado nas tabelas, que foi de $3,04 \mathrm{~m}^{3}$ por semana, e um fator de densidade de $230 \mathrm{~kg} / \mathrm{m}^{3}$, de acordo com os autores Silva e Santos, e aplicamos na fórmula apresentada abaixo:

$$
\begin{aligned}
& \mathrm{R}=\mathrm{D} \times \mathrm{V} \\
& \text { Onde: } \\
& \mathrm{R}=\text { peso do resíduo }(\mathrm{kg}) \\
& \mathrm{D}=\text { densidade aparente do resíduo }\left(\mathrm{kg} / \mathrm{m}^{3}\right) \\
& \mathrm{V}=\text { volume aparente do resíduo }\left(\mathrm{m}^{3}\right)
\end{aligned}
$$

O valor médio de geração encontrado foi de $699,2 \mathrm{~kg}$, que se refere à geração de resíduo comum por semana ( $\mathrm{Kg} / \mathrm{semana})$. Projetando esse valor para dados mensais, a carga resultante foi de $2.796,8 \mathrm{~kg} /$ mês e para dados diários $99,88 \mathrm{~kg} / \mathrm{dia}$. 
Quadro 6 - Média de Funcionários no Estabelecimento

\begin{tabular}{|l|c|c|c|}
\hline \multicolumn{4}{|c|}{ NÚMERO DE FUNCIONÁRIOS } \\
\hline \multicolumn{1}{|c|}{ TIPO } & MÊS & SEMANA & DIA \\
\hline Voluntários (flutuante) & 100 & 25 & $4^{*}$ \\
\hline Pacientes (fixo) & 7 & 7 & 7 \\
\hline Funcionários (fixo) & 4 & 4 & 4 \\
\hline TOTAL & $\mathbf{1 1 1}$ & $\mathbf{3 6}$ & $\mathbf{1 5}$ \\
\hline
\end{tabular}

* Entre três e quatro funcionários, porém adotamos 4.

Buscando adotar um critério (fator), que normalizasse a variação apresentada anteriormente foi realizada a pesagem dos resíduos comuns, e obteve-se uma média de geração de $38 \mathrm{~kg}$ referente a dois dias. Logo, a geração por dia é de $19 \mathrm{~kg}$ para as 15 pessoas, que resulta em 1,26 kg/hab.dia. Valor este, que apresenta maior confiabilidade quando comparado aos dados da literatura, porém este ainda não pode ser comparado visto que é referente apenas ao resíduo comum.

Foi feita também a pesagem do resíduo de serviços de saúde no ato da coleta da empresa coletora durante o período de um mês, acompanhando a frequência de coleta dos resíduos que é uma vez por semana.

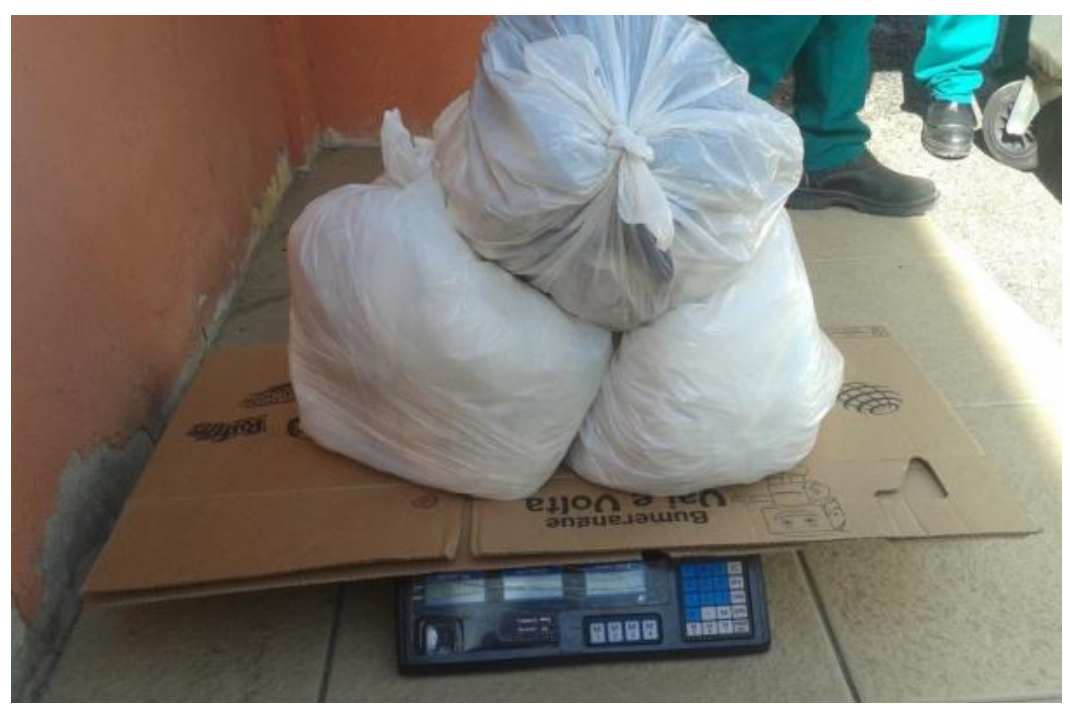

\section{Figura 5 - Pesagem do RSS.}

A pesagem dos resíduos de serviços de saúde foi realizada uma vez por semana, com uma balança digital da marca Multivisi com capacidade para $40 \mathrm{~kg}$ com precisão de $2 \mathrm{~g}$. Desta forma obteve-se uma média de geração diária, semanal e mensal, como mostra o quadro 7.

Quadro 7 - Quantificação de Resíduo de Serviços de Saúde

\begin{tabular}{|l|l|}
\hline Média de Geração & kg \\
\hline Dia & 5,21 \\
\hline Semana & 35,847 \\
\hline Mês & 143,388 \\
\hline
\end{tabular}


Para se obter o valor de geração de RSS por dia por pessoa, dividiu-se pelo número de pacientes (7) a geração diária, resultando em $0,73 \mathrm{~kg} / \mathrm{hab}$.dia.

Somando a geração diária por pessoa dos dois tipos de resíduos, comum e de serviço de saúde, temos $1,99 \mathrm{~kg} /$ hab.dia. Que é um valor coerente quando comparado à literatura, que é entre 1,6 e $1,7 \mathrm{~kg} / \mathrm{hab}$.dia.

Sendo assim, a geração mensal de resíduos totais da unidade estudada é de 181,388 kg, os Resíduos de Serviços de Saúde constituem aproximadamente 79\%.

\subsection{Diagnóstico da Situação Atual}

Durante o acompanhamento, constatou-se que os resíduos gerados no local de estudo são do grupo A (resíduos infectantes), grupo B (químicos), grupo D (resíduo comum) e grupo E (perfurocortantes).

Estão classificados como de grupo A os resíduos utilizados em atendimento aos pacientes como luva, gaze, curativos, fraldas, enfim, resíduos contaminados com sangue do paciente. Incluídos na classificação como de grupo B estão os remédios vencidos e produtos químicos. Classificados como de grupo D estão os resíduos comuns, como os gerados na cozinha e escritório. As lâminas e seringas utilizadas pelos pacientes ou em atendimento á eles estão classificadas como de grupo E.

A coleta de todos os tipos de resíduos é realizada pelo funcionário do turno, utilizando os EPIs necessários, quando o recipiente se encontra com a capacidade completa ou quase completa.

Os resíduos comuns, grupo D, após a geração são descartados em recipientes envolvidos com saco de lixo preto, que é coletado após sua capacidade estar quase completa, lacrado e levado para fora das dependências do estabelecimento, para aguardar a coleta da prefeitura em um recipiente apropriado.

Os resíduos infectantes, grupo A, depois de gerados são descartados em recipientes específicos para o tipo de resíduo, envolvidos com saco de lixo branco leitoso, como exige a norma vigente, porém sem o símbolo de identificação que a mesma norma exige. Quando a capacidade do recipiente está quase cheia, o saco é retirado, lacrado e levado para o contêiner de acondicionamento externo de RSS, onde aguarda a coleta da prefeitura.

Os resíduos do grupo B, químicos, também sofrem o mesmo processo descrito no parágrafo acima para os resíduos do grupo A.

Os resíduos do grupo E, as seringas, gerados na Central de Medicamentos, são provenientes do tratamento do paciente através de vacinas e são descartados em uma caixa rígida apropriada de acordo com a norma NBR 13853 (1997). A caixa é entregue em mãos durante a coleta junto dos resíduos de serviço de saúde depois de ser lacrada.

O contêiner de acondicionamento externo do RSS é constituído de material rígido com tampa, não possui ventilação, tampouco vias de acesso para vetores, e possui cor branca. A sua capacidade atende a geração do estabelecimento em até mais de duas semanas, lembrando que a coleta é feita semanalmente. $O$ contêiner está situado na parte externa do estabelecimento, próximo à cozinha, de baixo de uma marquise, sobre uma estrutura de cimento com piso de azulejo.Nenhum recipiente ou saco de acondicionamento dos resíduos de serviços de saúde possui identificação quanto ao risco oferecido.

Acompanhando a coleta do RSS, verificaram-se sacos de resíduo abertos, o que não pode ocorrer, pois pode contaminar o contêiner e dificultar o manuseio, além de 
oferecer riscos. Foi verificado também que dentro dos resíduos de serviço de saúde continha resíduos comuns como embalagens de remédio, revistas, papéis de escritório, entre outros, tornando clara a deficiência na segregação dos resíduos.

O treinamento de todos os funcionários é essencial, principalmente quanto aos riscos que o RSS oferece e sua forma de segregação, uma vez que a segregação é feita no descarte do resíduo e esse último é feito por todos os funcionários.

\section{Considerações Finais}

O objetivo do trabalho de desenvolver um PGRSS para a unidade estudada foi alcançado. As medidas foram propostas de acordo com as necessidades levantadas no estudo feito do objeto de estudo visando minimizar os impactos produzidos pelo descarte inadequado do resíduo de serviço de saúde, precaver quanto aos riscos apresentados no manejo incorreto desse tipo de resíduo, através do treinamento dos funcionários, e minimizar os custos e desperdícios no gerenciamento dos resíduos, através da diminuição da geração dos resíduos contaminados que necessitam de tratamento e estabelecimento do horário de coleta.

A unidade estudada demonstrou conhecimento e interesse quanto às normas vigentes, sendo observada desde o início do estudo a atenção em segregar os RSS. Porém a insuficiência de esclarecimento das normas mostrou ser a maior dificuldade, tornando a segregação ineficiente e fazendo com que as normas sejam cumpridas parcialmente.

Ressaltando-se que a gestão dos RSS influencia diretamente no volume de resíduo contaminado gerado, já que o manejo pode permitir o contato do material não contaminado com o material contaminado, incluindo no volume de resíduos de serviços de saúde resíduos comuns.

Conclui-se que a quantidade de resíduos gerados em um estabelecimento depende diretamente das diferentes atividades exercidas e do número de pessoas envolvidas. Diagnosticar e quantificar os resíduos de serviços de saúde não é simples e a maior dificuldade é achar mão de obra capacitada para a segregação.

Levando em consideração que o tema Resíduo de Serviço de Saúde não é discutido de forma clara, faltando esclarecimento das normas, o trabalho possui grande impacto nos tempos atuais. Esse é um assunto muito importante visto que a falta de conhecimento pode acarretar graves danos, desde contaminação do funcionário até poluição do solo e águas.

E por mais que nossa região sudeste, de acordo com o Panorama de Resíduos Sólidos da ABRELPE (2012), seja a que mais realiza coleta de RSS e a que possui relativamente o maior potencial tecnológico para o tratamento do resíduo de serviço de saúde, os geradores ainda não estão adequados totalmente às normas vigentes. Logo, muitos resíduos contaminados não recebem tratamento devido à falha na segregação e destinação, sendo destinados incorretamente para lixões e aterro sanitário.

Conclui-se que o planejamento e o gerenciamento dos resíduos são essenciais, principalmente quando se trata de resíduo que pode oferecer risco patogênico. Mas a implementação e fiscalização das etapas de gerenciamento do resíduo é essencial para se atingir o sucesso da aplicação do plano de gerenciamento de resíduos. 
Referências

AGÊNCIA NACIONAL DE VIGILÂNCIA SANITÁRIA (ANVISA). RDC no 306 : Dispõe sobre o Regulamento Técnico para o gerenciamento de resíduos de serviços de saúde. Brasil, 2004.

ASSOCIAÇÃO BRASILEIRA DE EMPRESAS DE LIMPEZA PÚBLICA E RESÍDUOSESPECIAIS (ABRELPE). Panorama dos Resíduos Sólidos no Brasil. São Paulo, 2012.

ASSOCIAÇÃO BRASILEIRA DE NORMAS TÉCNICAS (ABNT). NBR 10.004: Resíduos sólidos - Classificação. Rio de Janeiro, 2004. 1993.

.NBR 12.807: Resíduos de Serviços de Saúde - Terminologia. Rio de Janeiro, 1993.

.NBR 12.808:Resíduos de Serviços de Saúde - Classificação. Rio de Janeiro,

NBR 12.810: Coleta de Resíduos de Serviços de Saúde - Procedimento. Rio de Janeiro, 1993.

BRITISH BROADCASTING CORPORATION (Reino Unido). Infecções por HIV aumentam no Brasil:no mundo, 54\% têm vírus sem saber. 2014. Disponível em: <http://www.bbc.co.uk/portuguese/noticias/2014/07/140716_aids_relatorio_rb>. Acesso em: 28out. 2014.

BRASIL. Constituição (2010). Lei $n^{\circ}$ 12305, de 2 de agosto de 2010. Politica Nacional dos Resíduos Sólidos. Brasília, 2010.

CONSELHO NACIONAL DO MEIO AMBIENTE (Conama). Resolução Conama no 358: Dispõe sobre o tratamento e a disposição final dos resíduos dos serviços de saúde e dá outras providências. Brasil, 2005.

DEPARTAMENTO DE DST, AIDS E HEPATITES VIRAIS. AIDS No Brasil. Disponível em: <http://www.aids.gov.br/pagina/aids-no-brasil>. Acesso em: 28 out. 2014.

MINISTÉRIO DA SAÚDE (MS) E AGÊNCIA NACIONAL DE VIGILÂNCIA SANITÁRIA (ANVISA). Manual de Gerenciamento de Resíduos de Serviço de Saúde. Brasília: ANVISA, 2006.

FIOCRUZ. Banco de Imagem. Disponível em: <http://www.fiocruz.br/biosseguranca/Bis/StartBIS.htm>. Acesso em: 29 set. 2014.

SILVA, C.E.R. O Processo de Trabalho da Limpeza e Coleta Interna do Lixo Hospitalar na Emergência do Hospital Municipal Paulino Werneck. 1999. Dissertação de Mestrado - Escola Nacional de Saúde Pública, FIOCRUZ, Rio de Janeiro. Biblioteca virtual ENSP-FIOCRUZ. Disponível em: <http://portalteses.icict.fiocruz.br>. Acesso em: 29 set. 2014.

SILVA, M.F. Resíduos de Serviços de Saúde: Gerenciamento no Centro Cirúrgico, Central de Material e Centro de Recuperação Anestésica de Um Hospital do Interior Paulista. Ribeirão Preto, 2004. 